\title{
Safety Assessment of Mainstream Smoke of Herbal Cigarette
}

\author{
Jong Ho Bak, Seung Min Lee and Heung Bin Lim \\ Department of Industrial Crop Science and Technology, Chungbuk National University, Cheongju, Korea
}

(Received February 3, 2015; Revised March 18, 2015; Accepted March 24, 2015)

\begin{abstract}
Owing to the increase in price of cigarettes in Korea, herbal cigarettes have received increasing attention as a non-smoking aid; however, its safety has hardly been studied. We analyzed some of the toxic components in the mainstream smoke of herbal cigarettes, performed a mutagenicity test on smoke condensates for safety assessment, and compared the results with the corresponding values of a general cigarette with the same tar content. Herbal cigarette "A" was smoked using automatic smoking machine under ISO conditions in a manner similar to general cigarette "T". The tar content measured was higher than that inscribed on the outside of a package. The mainstream smoke of herbal cigarette " $A$ " did not contain detectable levels of tobacco-specific nitrosamines and nicotine. Carbon monoxide and benzo $(\alpha)$ pyrene contents in herbal cigarette " $\mathrm{A}$ " were higher than those in the general cigarette " $T$ ". The phenolic contents such as hydroquinone, resorcinol, and catechol in herbal cigarette " $\mathrm{A}$ " were higher than those in the general cigarette " $T$ ", but cresol contents in herbal cigarette " $A$ " were lower than those in the general cigarette " $T$ ". The content of aromatic amines such as 4-aminobiphenyl in herbal cigarette " $A$ " was higher than that in the general cigarette " $\mathrm{T}$ "; however, this difference was not statistically significant. On the other hand, 1-aminonaphthalene, 2-aminonaphthalene, and 3-aminobiphenyl contents in herbal cigarette " $\mathrm{A}$ " were lower than those in the general cigarette " $T$ ". The smoke condensates of herbal cigarette " $\mathrm{A}$ " exhibited a higher mutagenic potential than the condensates from the general cigarette " $T$ " at the same concentration. We concluded that the mainstream smoke of herbal cigarette contains some toxic components, the smoke condensates of herbal cigarettes are mutagenic similar to general cigarette because of combustion products, and that the evaluation of the chemical and biological safety of all types of herbal cigarettes available on the market.
\end{abstract}

Key words: Herbal cigarette, Safety, Assessment, Mainstream smoke, Toxic component, Mutagenicity test

\section{INTRODUCTION}

Cigarettes smoke is a complex mixture of chemical components, many of which are known to be present in trace concentrations (1). The various components are produced by thermal decomposition and thermal synthesis reactions occurring in the smoking process. There were 4,994 confirmed components in tobacco leaves and 5,311 confirmed components in cigarettes smoke (2). Many components identified in cigarette smoke were included in a list of hazardous components in the International Agency for

Correspondence to: Heung Bin Lim, Department of Industrial Crop Science and Technology, Chungbuk National University, Cheongju, Chungbuk 362-763, Korea

E-mail: heungbin@chungbuk.ac.kr

This is an Open-Access article distributed under the terms of the Creative Commons Attribution Non-Commercial License (http:// creativecommons.org/licenses/by-nc/3.0) which permits unrestricted non-commercial use, distribution, and reproduction in any medium, provided the original work is properly cited.
Research on Cancer (IARC). All 9 components of them in mainstream cigarettes smoke have an impact on the human body and are classified as carcinogen (Group 1), as well as the other 9 components of them are distinguished as likely carcinogen to humans (Group 2A). They also contain 48 components that are possible carcinogen to humans (Group 2B) (3-5). The World Health Organization (WHO) recognizes 18 components, Health Canada (HC) recognizes 44 components and the Food and Drug Administration (FDA) of the USA recognizes 101 components as components indispensable to control management. Generally tobacco scientists regard 44 toxic components as Hoffmann list (6). The quality of cigarettes smoke also is evaluated by biological toxicity tests instead of content of harmful components. Many biological toxicity tests such as genetic and cytotoxic have been conducted using cigarettes condensates (7). Salmonella typhimurium TA98, TA100, TA102, TA1535, and TA1537 have been used to repress the synthesis of specific amino acids for genotoxicity testing of cigarettes smoke. This method generated a morphological or functional muta- 
tion by impairing the DNA chromosomes that play an important role in short-term retrieval methods for predicting the carcinogenicity of the test substance (8).

The number of smokers who wish to stop smoking has increased in recent years and smoking cessation education has been conducted in many countries around the world. However, it has been reported that success has occurred in only $3 \sim 5 \%$ of smokers who wish to stop smoking during one year; this low success rate is attributed to the lack of will power and withdrawal symptoms due to nicotine dependence (9). Many smokers who wished to stop smoking use nicotine replacement therapy to help with withdrawal symptoms (10). Non-smoking aids, such as nicotine patches, nicotine gum, herbal cigarette and e-cigarette, are used to help smoker stop smoking. Research suggests that lots of smokers use herbal cigarette as a non-smoking aid in Korea (11). The sales volume of electronic cigarette and herbal cigarette according to G-market of on-line distribution industry in Korea have increased each 1,160\%, $118 \%$ in 2014, year-on-year. Also, sales volume of non-smoking aids is expected on the increase because of raise of cigarette price. Herbal cigarette contain herbs, instead of tobacco leaves, as the raw material. Various herbal cigarette are sold in the Korean commercial market. However, the safety and chemical composition of herbal cigarette smoke have been scarcely studied.

This study was performed to determine the contents of some major toxic components in the mainstream smoke of herbal cigarette " $\mathrm{A}$ " and to evaluate the mutagenicity of smoke condensates and compare them with the corresponding values of general cigarette " $\mathrm{T}$ " with the same tar level.

\section{MATERIALS AND METHODS}

Materials. Herbal cigarette "A", Artemisia (A), which is most favorite in Korea market, and general cigarette (T) with similar to tar content was used in this study. Selected cigarette had a length of $84 \mathrm{~mm}$ and a circumferential of $8 \mathrm{~mm}$. The tar and nicotine content of herbal cigarette " $\mathrm{A}$ " was marked as $5.5 \mathrm{mg} / \mathrm{cig}$ and $0 \mathrm{mg} / \mathrm{cig}$ on the outside of package, respectively. The tar and nicotine content of the general cigarette " $T$ " was indicated as $5.5 \mathrm{mg} / \mathrm{cig}$ and $0.6 \mathrm{mg} / \mathrm{cig}$ on the outside of package, respectively. All of the samples were conditioned for $48 \mathrm{hrs}$ at a temperature of $22 \pm 1{ }^{\circ} \mathrm{C}$ and a relative humidity of $60 \pm 3 \%$ in the conditioning room before smoking. The smoke was collected according to the ISO 3402 method at a temperature of $22 \pm$ $3^{\circ} \mathrm{C}$ and a relative humidity of $60 \pm 5 \%$ (12). Automatic smoking machines (ISO standardized products), RM 20 (Borgwaldt, Germany), SM 450 (Cerulean, UK) and SM 500 (Cerulean, UK), were used according to the ISO 3308 method under ISO standard smoking conditions, such as a puff volume of $35.0 \pm 0.3 \mathrm{~mL}$, a puff duration of $60 \pm 0.5$ sec, a puff interval of $2.00 \pm 0.02 \mathrm{sec}$ and a butt length of the filter tip paper plus $3 \mathrm{~mm}$ (13).

Measurement of the content of tar, nicotine and carbon monoxide (CO) in mainstream smoke. Isopropanol (Merck, Germany) was used as an extraction solvent in order to measure the content of tar, nicotine, and CO in the mainstream smoke. Reference nicotine was purchased from Sigma Aldrich co. (USA), and n-heptadecane (Sigma Aldrich, USA) was used as an internal standard to analyze the content of nicotine. Reference water was purchased from Merck co. (Germany), and ethanol (Merck, Germany) was used as an internal standard to measure the content of water. The smoke was collected using RM 20 automatic smoking machines (Borgwaldt, Germany), according to the ISO 3308 method (13). Total particulate matter (TPM) was calculated by measuring weight of the Cambridge filter pad (CFP; Borgwaldt, Germany), in the cigarettes holder, before and after smoking (14). The nicotine and water are extracted by adding trapped CFP and extraction solution into the flask, the supernatant was placed in a vial for analysis. The nicotine and water content were analyzed using a gas chromatograph 6890N (GC; Agilent Technologies, USA) according to the ISO 10315 and ISO 10362-1 method. According to the ISO 8454 method, the CO content was automatically measured by trapping gas in a gas bag that passed, through the smoke trap in a RM 20 equipped with a $\mathrm{CO}$ analyzer (Borgwaldt, Germany) (15-17).

Measurement of the content of aromatic amines in mainstream smoke. The extraction solvent used to analyze the aromatic amines in the mainstream smoke was 5\% hydrochloric acid. The reference substances were 1-aminonaphthalene, 2-aminonaphthalene, 3-aminobiphenyl, and 4aminobiphenyl (Sigma Aldrich, USA) and the internal standards were 2-aminonaphthalene-d7 and 4-aminobiphenyld9 (CDN Isotopes, Canada) to analyze the content of aromatic amines. The smoke was collected using SM 500 automatic smoking machines (Cerulean, UK) according to the ISO 3308 method (13). The content of aromatic amines was analyzed using GC/MS 5975 (Agilent Technologies, USA) according to the HC T-102 method (18).

Measurement of the content of benzo[ $\alpha]$ pyrene $(B[\alpha] P)$ in mainstream smoke. Methanol (Merck, Germany) was used as an extraction solvent to analyze the content of $\mathrm{B}[\alpha] \mathrm{P}$ in the mainstream smoke. The reference substance was $\mathrm{B}[\alpha] \mathrm{P}$ (Sigma Aldrich, USA) and the internal standard was $B[\alpha] \mathrm{P}-\mathrm{d} 12$ (Sigma Aldrich, USA) to analyze the content of $\mathrm{B}[\alpha] \mathrm{P}$. The smoke was collected using SM 500 automatic smoking machines (Cerulean, UK) according to the ISO 3308 method (13). The content of $\mathrm{B}[\alpha] \mathrm{P}$ was analyzed using GC/MS 5975 (Agilent Technologies, USA) according to the ISO 22634 method (19). 


\begin{abstract}
Measurement of the content of phenolic compounds in mainstream smoke. The extraction solvent used to analyze the phenolic compounds in the mainstream smoke was $1 \%$ acetic acid solution in $100 \mathrm{mM}$ ascorbic acid. The reference substances were resorcinol, phenol, hydroquinone, catechol, o-cresol, p-cresol and m-cresol (Sigma Aldrich, USA) to analyze the content of phenolic compounds. The smoke was collected using SM 500 automatic smoking machines (Cerulean, UK) according to the ISO 3308 method (13). The content of phenolic compounds was analyzed using HPLC 1100 Series (Agilent Technologies, USA) according to the HC T-114 method (20).
\end{abstract}

\section{Measurement of the content of tobacco specific nitro- samines (TSNAs) in mainstream smoke. The extraction solvent used to analyze the TSNAs in the mainstream smoke was $100 \mathrm{mM}$ ammonium acetate. The reference sub- stances were 4-(N-nitrosomethylamino)-1-(3-pyridyl)-1- butanone (NNK), N-nitrosonornicotine (NNN), N-nitrosoa- natabine (NAT) and N-nitrosoanabasine (NAB) (Sigma Aldrich, USA) to analyze the content of TSNAs. The smoke was collected using SM 450 automatic smoking machines (Cerulean, UK) according to the ISO 3308 method (13). The content of TSNAs was analyzed using HPLC/MS/MS API 4000 (AB SCIEX, USA) according to the CORESTA Recommended Method $\mathrm{N}^{\mathrm{o}} 75$ (21).}

Mutagenicity test. Salmonella typhimurium TA98 strain (frameshift mutation) was tested for genetic traits such as histidine requirement, sensitivity to crystal violet ( $\mathrm{rfa}$ ), ampicillin resistance and sensitivity to UV light (uvrB mutation) prior to use (22). Dimethyl sulfoxide (DMSO), agar, glucose, 2-aminoanthracene(2-AA), L-biotin, L-histidine, citric acid monohydrate, potassium phosphate dibasic anhydrous $\left(\mathrm{K}_{2} \mathrm{HPO}_{4}\right)$, crystal violet, magnesium sulfate $\left(\mathrm{MgSO}_{4} \cdot 7 \mathrm{H}_{2} \mathrm{O}\right)$, sodium ammonium hydrogen phosphate $\left(\mathrm{NaNH}_{4} \mathrm{HPO}_{4} \cdot 4 \mathrm{H}_{2} \mathrm{O}\right)$, and ampicillin were purchased from Sigma Co (St Louis, USA), S-9 (protein content : $23.6 \mathrm{mg} /$ $\mathrm{mL}$ ) was purchased from Moltox Co (USA) and S-9 cofactor was purchased from Oriental Yeast Co (Japan).

To determine the suitability of the strains verification tests were performed in four ways. The histidine requirement confirmed whether S. Typhimurium TA98 grew in minimal glucose agar (MGA), biotin, and histidine/biotin plates after incubation at $37^{\circ} \mathrm{C}$ for $12 \mathrm{hr}$. For the $u v r B$ mutation, after inoculating the cultured S. Typhimurium TA98 on the nutrient agar plate, half of the nutrient agar plate was covered with aluminum foil and exposed to ultraviolet radiation $(15 \mathrm{~W})$ at a distance of $33 \mathrm{~cm}$ for $8 \mathrm{sec}$. After $12 \mathrm{hr}$ of incubation, the portion exposed to ultraviolet radiation was examined to determine whether any growth had occurred. Cultured S. Typhimurium TA98 $(100 \mu \mathrm{L})$ was added to the top agar $(2 \mathrm{~mL})$, gently vortexed, and spread evenly on the nutrient agar plate. A sterile filter paper disk was placed in the center of the plate and $5 \mu \mathrm{L}$ of crystal violet $(2 \mathrm{mg} / \mathrm{mL})$ was dropped on the disk and allowed to absorb. After $12 \mathrm{hr}$ of incubation at $37^{\circ} \mathrm{C}$, the diameter of the growth inhibition ring around the disk was measured. R-factor plasmid confirmed whether S. Typhimurium TA98 grew on an ampicillin plate after incubation at $37^{\circ} \mathrm{C}$ for $12 \mathrm{hr}$.

The smoke was collected using RM 20 automatic smoking machines (Borgwaldt, Germany) according to the ISO 3308 method (13). The concentration of smoke condensate in the mainstream smoke was extracted by adding trapped smoke condensate in CFP with into the flask with DMSO as a concentration of $4 \mathrm{mg} / \mathrm{mL}$. After removing the bacteria from the extracted smoke condensate using a $0.22 \mu \mathrm{m}$ syringe filter (Sartorius Stedim, Germany), the sample was diluted to a concentration of $200 \mu \mathrm{g} / \mathrm{mL}$ in a micro-centrifuge tube (SPL, Korea). The mutagenicity test was conducted using S. Typhimurium TA98, which is a modified Ames test (22) First, $100 \mu \mathrm{L}$ of the S. Typhimurium TA98 strain $\left(1 \sim 2 \times 10^{9}\right.$ cells $\left./ \mathrm{mL}\right)$ was cultured in a sterile test tube for $12 \mathrm{hr}$, and $100 \mu \mathrm{L}$ of each sample was placed in a sterile cap tube, to which $500 \mu \mathrm{L}$ of S-9 mix was added for the metabolic activation-requiring of the indirect mutagen test. Then, $2 \mathrm{~mL}$ of $45^{\circ} \mathrm{C}$ top agar was added to each mixture, gently stirred, and uniformly spread on minimal agar, followed by $48 \mathrm{hr}$ of incubation in the incubator at $37^{\circ} \mathrm{C}$. The positive controls 2 -AA $(1 \mu \mathrm{g} /$ plate) served as the indirect mutagen.

Statistical analysis. Data were analyzed by one-way ANOVA followed by Dunnett's multiple comparison test (using SPSS version 14.0 statistical software). Differences were considered statistically significant if P-values were $<0.05$ and $<0.01$ by using ANOVA. The difference between the herbal cigarette "A" and general cigarette "T" was clearly distinguishable, and therefore, statistical significance if comparisons between the herbal cigarette " $\mathrm{A}$ " and general cigarette " $T$ " has not been indicated.

\section{RESULTS AND DISCUSSION}

The content of tar, nicotine and $\mathrm{CO}$ in mainstream smoke. Tar is TPM after deduction of its water and nicotine content in cigarette smoke and a black mixture of hydrocarbons and free carbon obtained from a wide variety of organic materials through destructive distillation. Nicotine is transferred directly into aerosol during smoking at a temperature of approximately $220^{\circ} \mathrm{C}$ from a tobacco leaf. $\mathrm{CO}$ is known to be generated by incomplete combustion at a high temperature of approximately $700^{\circ} \mathrm{C}(23,24)$. Nicotine and $\mathrm{CO}$ are not confirmed in the evaluation of carcinogenic levels of the IARC. The oral $\mathrm{LD}_{50}$ of nicotine is $50 \mathrm{mg} / \mathrm{kg}$. Nicotine is known to induce addiction, and CO can cause fatal poisoning at a low concentration of approximately $667 \mu \mathrm{g} / \mathrm{mL}$. CO poisoning causes coronary artery 
Table 1. The contents of tar, nicotine and $\mathrm{CO}$ in mainstream smoke

\begin{tabular}{lrcc}
\hline \hline Compounds & \multicolumn{1}{c}{ 3R4F } & "T" & "A" \\
\hline TPM (mg/cig) & $10.39 \pm 0.10$ & $7.15 \pm 0.14$ & $8.33 \pm 0.14$ \\
Tar (mg/cig) & $8.38 \pm 0.07$ & $6.02 \pm 0.11$ & $7.45 \pm 0.18$ \\
Nicotine (mg/cig) & $0.73 \pm 0.02$ & $0.57 \pm 0.02$ & $\mathrm{~N} / \mathrm{d}$ \\
CO (mg/cig) & $12.53 \pm 0.06$ & $6.07 \pm 0.25$ & $12.30 \pm 0.30^{* *}$ \\
\hline
\end{tabular}

Values are expressed as mean \pm S.E. $(n=3)$. Statistical analysis of data was performed using ANOVA.

${ }^{* *}: p<0.01$ compared with control group.

3R4F: Reference cigarette. "T": general cigarette with the contents same tar. "A": herbal cigarette made in Artemisia as raw material. $\mathrm{N} / \mathrm{d}$ : Not Detected.

disease, such as angina pectoris or myocardial infarction due to anoxia.

The contents of tar, nicotine, and $\mathrm{CO}$ in mainstream smoke of herbal cigarette " $\mathrm{A}$ " and general cigarette " $\mathrm{T}$ " are shown in Table 1. The indicated contents of tar, nicotine, and $\mathrm{CO}$ on the certification of the reference cigarette were $9.5 \mathrm{mg} / \mathrm{cig}, 0.73 \mathrm{mg} / \mathrm{cig}$ and $12.0 \mathrm{mg} / \mathrm{cig}$, respectively. The measured contents of the tar, nicotine, and $\mathrm{CO}$ of the reference cigarette were $8.38 \pm 0.07 \mathrm{mg} / \mathrm{cig}, 0.73 \pm 0.02 \mathrm{mg} / \mathrm{cig}$ and $12.53 \pm 0.06 \mathrm{mg} / \mathrm{cig}$, respectively. The indicated contents of tar and nicotine on the package of general cigarette "T" were $5.5 \mathrm{mg} / \mathrm{cig}$ and $0.60 \mathrm{mg} / \mathrm{cig}$, respectively. The measured contents of the tar, nicotine and $\mathrm{CO}$ of general cigarette "T" were $6.02 \pm 0.11 \mathrm{mg} / \mathrm{cig}, 0.57 \pm 0.02 \mathrm{mg} / \mathrm{cig}$ and $6.07 \pm 0.25 \mathrm{mg} / \mathrm{cig}$, respectively. They satisfied the tolerance range (package value $\pm 20 \%$ ) of tar and nicotine. Meanwhile, the indicated contents of the tar and nicotine on the package of herbal cigarette " $\mathrm{A}$ " were $5.5 \mathrm{mg} / \mathrm{cig}$ and $0 \mathrm{mg} / \mathrm{cig}$, respectively. The measured contents of tar of herbal cigarette " $\mathrm{A}$ " was $7.45 \pm 0.18 \mathrm{mg} / \mathrm{cig}$, which exceed the tolerance range (package value $\pm 20 \%$ ) of tar in Korean tobacco business law. However, nicotine of herbal cigarette "A" was not detected. The content of $\mathrm{CO}$ of herbal cigarette "A" was $12.30 \pm 0.30 \mathrm{mg} / \mathrm{cig}$.

We confirmed that tar and $\mathrm{CO}$ are present in the mainstream smoke of herbal cigarette " $\mathrm{A}$ ", nicotine is not detected, and the $\mathrm{CO}$ content of herbal cigarette is higher than that of the general cigarette " $T$ " with the same tar level.
The content of aromatic amines in mainstream smoke. Aromatic amines are formed under the pyrolysis conditions underwent nitrogen at temperatures of approximately $650^{\circ} \mathrm{C}$ produces during smoking (25). Aromatic amines are a compound which bonded an amino group in the aromatic ring and have high toxicity. 1-Aminonaphthalene is a component of the herbicide and respiratory, and is not confirmed in the carcinogenic of the IARC. The inhalation $\mathrm{LC}_{50}$ (mouse) for $4 \mathrm{hr}$ of 1 -aminonaphthalene is $0.056 \mathrm{mg} / \mathrm{m}^{3} .2-$ Aminonaphthalene causes bladder cancer and is a carcinogen in group 1 in the carcinogenic of the IARC. The oral $\mathrm{LD}_{50}$ (mouse) of 2-aminonaphthalene is $727 \mathrm{mg} / \mathrm{kg}$ (3). 3Aminobiphenyle stimulates respiratory system, and is not confirmed in the carcinogenic of the IARC. The oral $\mathrm{LD}_{50}$ (mouse) of 3-aminobiphenyl is $331 \mathrm{mg} / \mathrm{kg}$. 4-Aminobiphenyl uses a dye and affects the nutritional metabolites and is a carcinogen in group 1 in the carcinogenic of the IARC. The oral $\mathrm{LD}_{50}$ (mouse) of 4-aminobiphenyl is $500 \mathrm{mg} / \mathrm{kg}$ (3).

The contents of aromatic amine in mainstream smoke of herbal cigarette " $\mathrm{A}$ " and general cigarette " $\mathrm{T}$ " are shown in Table 2. The measured content of 1-aminonaphthalene in the reference cigarette was $16.67 \pm 0.33 \mathrm{ng} / \mathrm{cig}$ similar to the results of Chen and Moldoveanu (26). The measured contents of 1-aminonaphthalene, 2-aminonaphthalene, 3aminobiphenyl and 4-aminobiphenyl among the aromatic amine components of the general cigarette " $T$ " were $12.60 \pm$ $0.16 \mathrm{ng} / \mathrm{cig}, 7.48 \pm 0.23 \mathrm{ng} / \mathrm{cig}, 1.52 \pm 0.04 \mathrm{ng} / \mathrm{cig}$ and $0.89 \pm$ $0.03 \mathrm{ng} / \mathrm{cig}$, respectively. Meanwhile, the measured contents of 1-aminonaphthalene, 2-aminonaphthalene, 3-aminobiphenyl and 4-aminobiphenyl among the aromatic amine components of herbal cigarette " $A$ " were $8.23 \pm 0.92 \mathrm{ng} /$ cig, $4.94 \pm 0.36 \mathrm{ng} / \mathrm{cig}, 1.12 \pm 0.14 \mathrm{ng} / \mathrm{cig}$ and $1.12 \pm 0.14$ $\mathrm{ng} / \mathrm{cig}$, respectively.

We confirmed that herbal cigarette " $\mathrm{A}$ " contains 4 toxic aromatic amines in the mainstream smoke and their contents were relatively low compared to the general cigarette " $T$ " with the same tar level.

The content of $B[\alpha] P$ in mainstream smoke. $B[\alpha] P$ are formed under the pyrolysis conditions at temperatures of approximately $860^{\circ} \mathrm{C}$ produces during smoking (27). $\mathrm{B}[\alpha] \mathrm{P}$ is a compound which become metabolic activation in

Table 2. The contents of aromatic amines in mainstream smoke

\begin{tabular}{|c|c|c|c|c|}
\hline Group & Compound & 3R4F & "T" & "A" \\
\hline \multirow{4}{*}{$\begin{array}{l}\text { Aromatic amine } \\
\qquad(\mathrm{ng} / \mathrm{cig})\end{array}$} & 1-Aminonaphthalene & $16.67 \pm 0.33$ & $12.60 \pm 0.16$ & $8.23 \pm 0.92^{* * *}$ \\
\hline & 2-Aminonaphthalene & $11.97 \pm 0.17$ & $7.48 \pm 0.23$ & $4.94 \pm 0.36^{* *}$ \\
\hline & 3-Aminobiphenyl & $1.96 \pm 0.05$ & $1.52 \pm 0.04$ & $1.12 \pm 0.14^{* *}$ \\
\hline & 4-Aminobiphenyl & $1.95 \pm 0.09$ & $0.89 \pm 0.03$ & $1.00 \pm 0.11$ \\
\hline
\end{tabular}

Values are expressed as mean \pm S.D. $(n=3)$. Statistical analysis of data was analyzed using ANOVA.

${ }^{* *}: p<0.01$ compared with control group.

3R4F: reference cigarette. "T": general cigarette with the contents same tar. " $\mathrm{A}$ ": herbal cigarette made in Artemisia as raw material. 
vivo in poly-nuclear aromatic hydrocarbons and bind DNA in the human body and can cause infertility by acting on endocrine system, and is a carcinogen in group 1 in the carcinogenic of the IARC. The skin $\mathrm{LD}_{50}$ (mouse) of $\mathrm{B}[\alpha] \mathrm{P}$ is $50 \mathrm{mg} / \mathrm{kg}(3)$.

The content of $\mathrm{B}[\alpha] \mathrm{P}$ in mainstream smoke of herbal cigarette " $\mathrm{A}$ " and general cigarette " $\mathrm{T}$ " is shown in Table 3. The content of $\mathrm{B}[\alpha] \mathrm{P}$ in the reference cigarette was $14.11 \pm$ $0.32 \mathrm{ng} / \mathrm{cig}$ similar to the results of Chen and Moldoveanu (26). The measured content of $\mathrm{B}[\alpha] \mathrm{P}$ of the general cigarette "T" was $2.29 \pm 0.09 \mathrm{ng} / \mathrm{cig}$. Meanwhile, the content of $\mathrm{B}[\alpha] \mathrm{P}$ of herbal cigarette " $\mathrm{A}$ " was $2.77 \pm 0.21 \mathrm{ng} / \mathrm{cig}$.

We confirmed the presence of $\mathrm{B}[\alpha] \mathrm{P}$ in the mainstream smoke of herbal cigarette " $\mathrm{A}$ " and its content is relatively higher than the general cigarette " $T$ " with the same tar level.
Table 3. The contents of $\mathrm{B}[\alpha] \mathrm{P}$ in mainstream smoke

\begin{tabular}{cccc}
\hline \hline Compound & 3R4F & "T" & "A" \\
\hline $\mathrm{B}[\alpha] \mathrm{P}(\mathrm{ng} /$ cig) & $4.11 \pm 0.32$ & $2.29 \pm 0.09$ & $2.77 \pm 0.21^{*}$ \\
\hline
\end{tabular}

Values are expressed as mean \pm S.D. $(n=3)$. Statistical analysis of data was analyzed using ANOVA.

${ }^{*}: p<0.05$ compared with control group.

3R4F: reference cigarette. "T": general cigarette with the contents same tar. "A": herbal cigarette made in Artemisia as raw material.

The content of phenolic compounds in mainstream smoke. Phenolic compounds are formed under the pyrolysis conditions at temperatures of approximately $860^{\circ} \mathrm{C}$ produced during smoking (27). Phenolic compounds have a peculiar smell because of a compound that combined

Table 4. The contents of phenolic compounds in mainstream smoke

\begin{tabular}{|c|c|c|c|c|}
\hline Group & Compound & 3R4F & "T" & "A" \\
\hline \multirow{6}{*}{$\begin{array}{l}\text { Phenolic compound } \\
(\mu \mathrm{g} / \mathrm{cig})\end{array}$} & Hydroquinone & $32.49 \pm 1.61$ & $27.03 \pm 0.04$ & $72.11 \pm 3.48^{\text {*** }}$ \\
\hline & Resorcinol & $0.81 \pm 0.04$ & $0.79 \pm 0.06$ & $1.12 \pm 0.01^{* * *}$ \\
\hline & Catechol & $41.79 \pm 1.25$ & $39.78 \pm 1.27$ & $57.15 \pm 2.85^{* * *}$ \\
\hline & Phenol & $9.91 \pm 0.70$ & $14.86 \pm 0.88$ & $13.44 \pm 0.55$ \\
\hline & $\mathrm{M}+\mathrm{p}-\mathrm{Cresol}$ & $7.47 \pm 0.54$ & $8.34 \pm 0.30$ & $4.86 \pm 0.13^{* *}$ \\
\hline & O-Cresol & $2.82 \pm 0.16$ & $3.00 \pm 0.12$ & $1.60 \pm 0.07^{* *}$ \\
\hline
\end{tabular}

Values are expressed as mean \pm S.D. $(n=3)$. Statistical analysis of data was analyzed using ANOVA.

${ }^{*}: p<0.05$ and ${ }^{* *}: p<0.01$ compared with control group.

3R4F: reference cigarette. "T": general cigarette with the contents same tar. "A": herbal cigarette made in Artemisia as raw material.

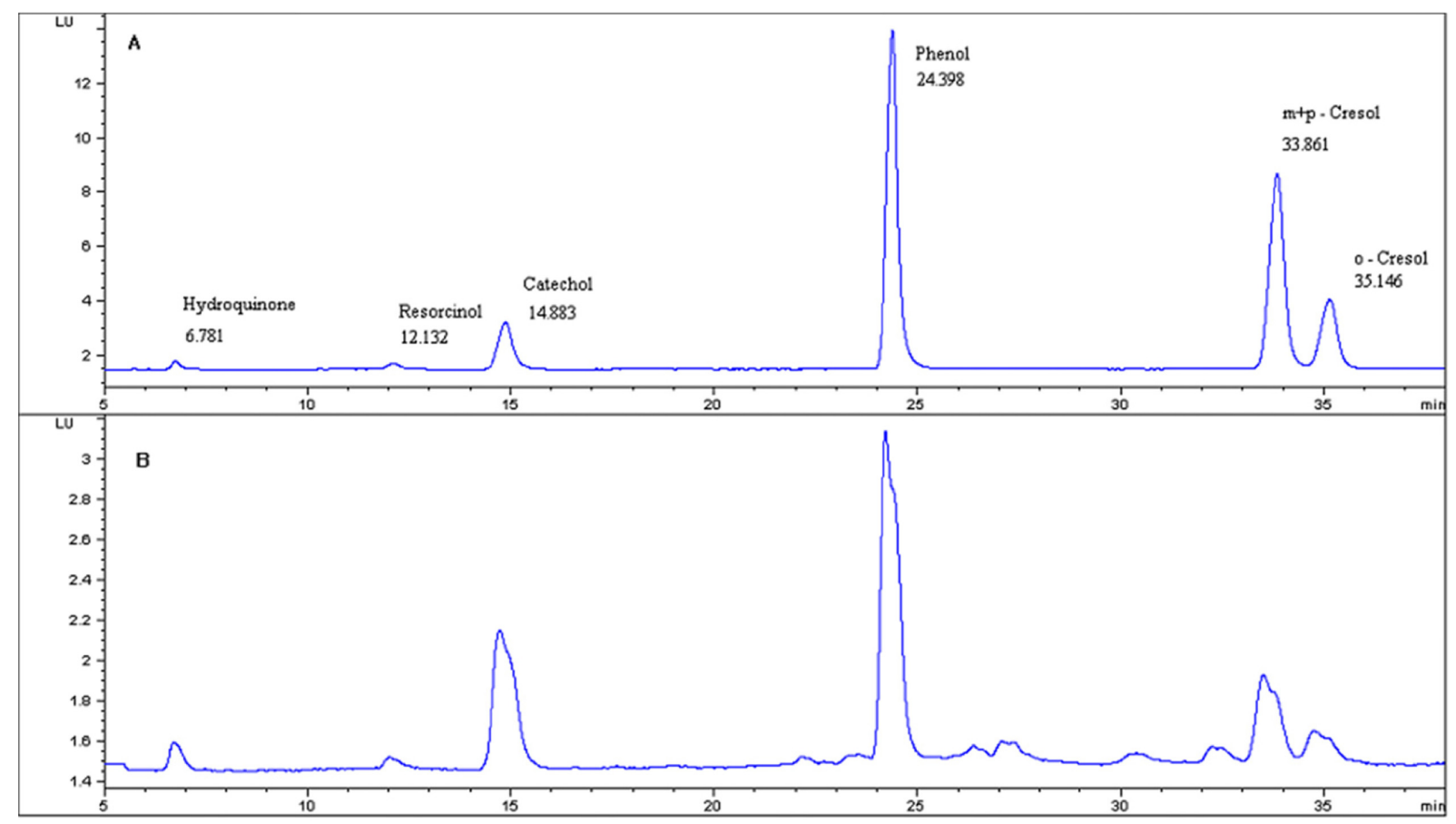

Fig. 1. Chromatograms of phenolic compounds. A shows the chromatogram for the standard solution. $B$ shows the chromatogram for the herbal cigarette " $\mathrm{A}$ " of phenolic compounds. 
hydroxyl group in the aromatic ring, and are toxic. Hydroquinone is a component affecting the central nervous system inducing damage to the eyes and causing skin irritations, and is not confirmed in the carcinogenic of the IARC. The oral $\mathrm{LD}_{50}$ (mouse) of hydroquinone is $317 \mathrm{mg} / \mathrm{kg}$. Resorcinol cause hearing impairment and convulsions, phenol causes damage to liver function by affecting the central nervous system and are not confirmed in the carcinogenic of the IARC. The oral $\mathrm{LD}_{50}$ (mouse) of resorcinol and phenol are $302 \mathrm{mg} / \mathrm{kg}$ and $301 \mathrm{mg} / \mathrm{kg}$, respectively. Catechol is a component affecting the respiratory system, is applied to an oxidant of the dye owing to easy oxidation, and is a possible carcinogens in group $2 \mathrm{~B}$ in the carcinogenic of the IARC. The oral $\mathrm{LD}_{50}$ (mouse) of catechol is $260 \mathrm{mg} / \mathrm{kg}$ (5). O-cresol, m-cresol and p-cresol are components that cause damage to the nose and lungs and are not confirmed in the carcinogenic of the IARC. The oral $\mathrm{LD}_{50}$ (mouse) of ocresol, m-cresol and p-cresol are $121 \mathrm{mg} / \mathrm{kg}, 242 \mathrm{mg} / \mathrm{kg}$, and $207 \mathrm{mg} / \mathrm{kg}$, respectively.

The contents of phenolic compound in mainstream smoke of herbal cigarette " $\mathrm{A}$ " and general cigarette " $\mathrm{T}$ " are shown in Table 4. Fig. 1 shows the chromatograms for the standard solution and herbal cigarette "A". The measured content of hydroquinone in the reference cigarette was $32.49 \pm$ $1.61 \mu \mathrm{g} / \mathrm{cig}$ similar to the results of Chen and Moldoveanu (26). The measured contents of hydroquinone, resorcinol, catechol, phenol, $\mathrm{m}+\mathrm{p}$-Cresol, and o-Cresol among the phenolic components of the general cigarette " $\mathrm{T}$ " were $27.03 \pm 0.04 \mu \mathrm{g} / \mathrm{cig}, 0.79 \pm 0.06 \mu \mathrm{g} / \mathrm{cig}, 39.78 \pm 1.27 \mu \mathrm{g} / \mathrm{cig}$, $14.86 \pm 0.88 \mu \mathrm{g} / \mathrm{cig}, 8.34 \pm 0.30 \mu \mathrm{g} / \mathrm{cig}$, and $3.00 \pm 0.12 \mu \mathrm{g} /$ cig, respectively. Meanwhile, the measured contents of hydroquinone, resorcinol, catechol, phenol, $\mathrm{m}+\mathrm{p}$-cresol, and o-cresol among the phenolic components of herbal cigarette "A" were $72.11 \pm 3.48 \mu \mathrm{g} / \mathrm{cig}, 1.12 \pm 0.01 \mu \mathrm{g} / \mathrm{cig}$, $57.15 \pm 2.85 \mu \mathrm{g} / \mathrm{cig}, \quad 13.44 \pm 0.55 \mu \mathrm{g} / \mathrm{cig}, \quad 4.86 \pm 0.13 \mu \mathrm{g} /$ cig, and $1.60 \pm 0.07 \mu \mathrm{g} / \mathrm{cig}$, respectively.

We confirmed that herbal cigarette "A" contains various toxic phenolic compounds in the mainstream smoke, and while the levels of some phenolic compounds such as hydroquinone, resorcinol and catechol are relatively high, the levels of other phenolic compounds such as o-cresol and $\mathrm{m}+\mathrm{p}$-cresol are low compared to general cigarette "T" with the same tar level.

The content of TSNAs in mainstream smoke. TSNAs are formed by combining a secondary amine and nitrite with a produced substance during drying process and the process of machining of alkaloid such as nicotine, nornicotine, anatabine and anabasine in the tobacco leaf by the pyrolysis (28). TSNAs are known as the causative agent of oral perforation and liver, pancreas, lung and oral cancer. NNN and NNK, in particular, and are a carcinogen in group 1 in the carcinogenic of the IARC (3). NAT and NAB are not confirmed in the carcinogenic levels of the IARC. Com-
Table 5. The contents of TSNAs in mainstream smoke

\begin{tabular}{rcrrr}
\hline \hline Group & Compounds & \multicolumn{1}{c}{ 3R4F } & \multicolumn{1}{c}{ "T" } & "A" \\
\hline \multirow{3}{*}{ TSNAs } & NNN & $116.22 \pm 4.44$ & $45.78 \pm 9.33$ & N/d \\
(ng/cig) & NAT & $106.22 \pm 6.81$ & $41.62 \pm 7.24$ & N/d \\
& NAB & $10.64 \pm 0.63$ & $4.72 \pm 0.33$ & N/d \\
& NNK & $95.11 \pm 8.57$ & $16.38 \pm 1.39$ & N/d \\
\hline
\end{tabular}

3R4F: reference cigarette. "T": general cigarette with the contents same tar. " $A$ ": herbal cigarette made in Artemisia as raw material. $\mathrm{N} / \mathrm{d}$ : not detected.

NNN: N-Nitrosonornicotine. NAT: N-Nitrosoanatabine. NAB: NNitrosoanabasine. NNK: 4-(N-Nitrosomethylamino)-1-(3-pyridyl)-1butanone.

ponents are the most representative carcinogen in the cigarettes smoke.

The contents of TSNA in mainstream smoke of herbal cigarette "A" and general cigarette " $\mathrm{T}$ " are shown in Table 5. The measured content of NNN in the reference cigarette was $116.22 \pm 4.44 \mathrm{ng} / \mathrm{cig}$ similar to the results of Chen and Moldoveanu (26). The measured contents of NNN, NAT, $\mathrm{NAB}$, and NNK among the TSNA components of the general cigarette " $T$ " were $45.78 \pm 9.33 \mathrm{ng} / \mathrm{cig}, 41.62 \pm 7.24 \mathrm{ng} /$ cig, $4.72 \pm 0.33 \mathrm{ng} / \mathrm{cig}$, and $16.38 \pm 1.39 \mathrm{ng} / \mathrm{cig}$, respectively. Meanwhile, the TSNAs were not detected of herbal cigarette "A".

We confirmed that the toxic TSNAs are not detected in the mainstream smoke of general cigarette "T" with the same tar level.

Mutagenicity test. The histidine requirement test was performed in a plate supplemented with histidine using $S$. Typhimurium TA98 strains that were histidine auxotrophic mutants of S. Typhimurium LT-2. The Typhimurium TA98 strains grew on a histidine/biotin plate, but did not grow on a MGA plate and a biotin plate (Fig. 2). UvrB mutation test was also conducted to examine the sensitivity to UV test must be not formed only in a portion UV of the radiation by S. Typhimurium TA98 strains. In this test, the S. Typhimurium TA98 did not grow on the UV-exposed portions of the plates, but grew on the portions that were not exposed to UV light (Fig. 2). The $r f a(\Delta)$ mutation test was conducted in which the mutation is indicated when the diameter of the growth suppression ring around the filter paper disc was greater than $14 \mathrm{~mm}$. In the this test, the diameter of the growth suppression ring that formed around the filter paper disc was up to $16 \mathrm{~mm}$ (Fig. 2). The R-factor confirmation test was performed using a strain that has the pKM101 plasmid, which is resistant to ampicillin. The results of the test confirmed normal growth of the S. Typhimurium TA98 strain on an ampicillin plate (Fig. 2). Therefore, the suitability of the S. Typhimurium strain TA98 for this study was confirmed through genetic traits tests.

To establish the optimal concentration of the inducer for mutagenic experiments prior to this test, the experiment was 


\section{Histidine requirement}

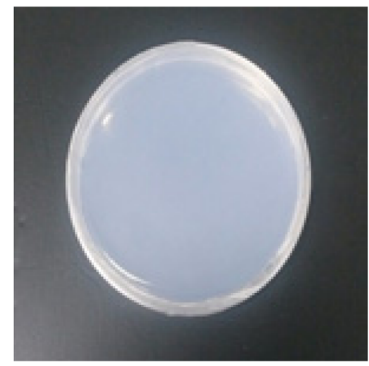

MGA plate

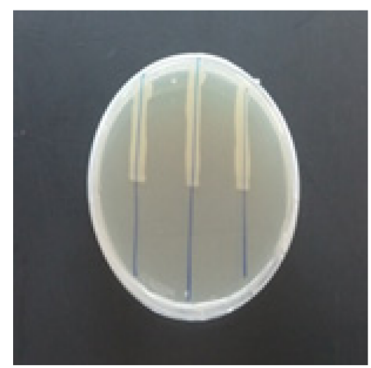

UvrB mutation

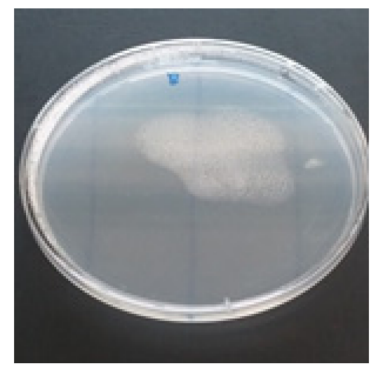

Biotin plate

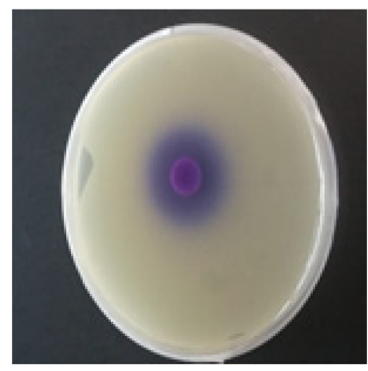

Rfa $(\Delta)$ mutation

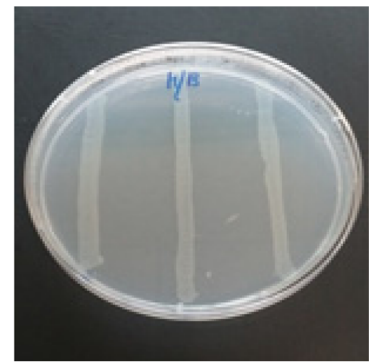

Histidine/Biotine plate

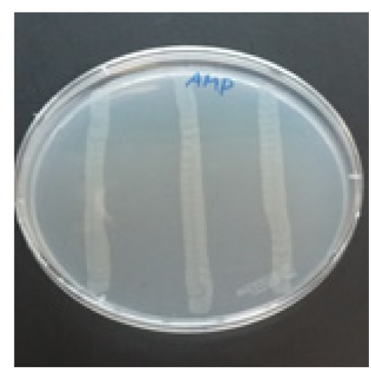

Ampicillin resistance

Fig. 2. Genetic traits test of S. Typhimurium TA98. Genetic traits test was indicated activation of S. Typhimurium TA98. MGA plate; Minimal glucose agar plate, Biotine plate; $0.5 \mathrm{mM}$ Biotine solution $(122.1 \mu \mathrm{g} / \mathrm{mL})$, Histidine/Biotine Plate; $0.5 \mathrm{mM}$ Biotine solution (122.1 $\mu \mathrm{g} /$ $\mathrm{mL})$ and Histidine solution $(5 \mathrm{mg} / \mathrm{mL})$, UvrB mutation plate; Exposed to ultraviolet radiation $(15 \mathrm{~W})$ at a distance of $33 \mathrm{~cm}$ for $8 \mathrm{sec}$, $\mathrm{rfa}(\Delta)$ mutation plate; Dropped on $5 \mu \mathrm{l}$ of crystal violet solution $(2 \mathrm{mg} / \mathrm{mL})$, Ampicillin plate; Ampicillin solution $(10 \mathrm{mg} / \mathrm{mL}$ of 0.02 sodium hydroxide).

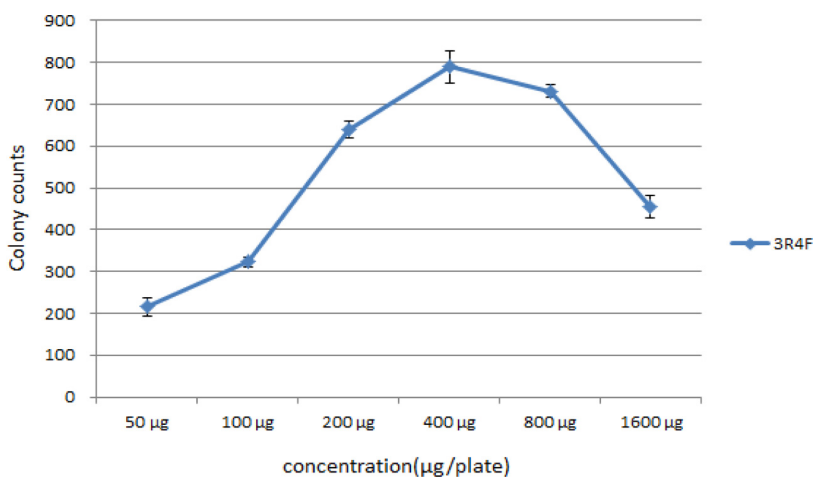

Fig. 3. Change of revertant colony number with smoke condensate concentration in mutagenicity test. The S. Typhimurium strains TA98 were treated with the indicated concentration of 3R4F smoke condensate for $48 \mathrm{hr}$. Values are expressed as a mean \pm S.D $(\mathrm{N}=3)$.

repeated three times at each of the following concentrations of smoke condensate; 50, 100, 200, 400, 800 and $1600 \mu \mathrm{g} /$ plate using a $3 \mathrm{R} 4 \mathrm{~F}$ of reference cigarette. The number of revertant colonies of smoke condensate in mainstream smoke of the reference cigarette is shown in Fig. 3. The number of revertant colonies in the concentration of $50 \mu \mathrm{g} /$ plate was $215.0 \pm 20.2$, concentration of $100 \mu \mathrm{g} /$ plate was $323.0 \pm 12.5$, concentration of $200 \mu \mathrm{g} /$ plate was $639.7 \pm$
19.9 and concentration of $400 \mu \mathrm{g} /$ plate was $789.7 \pm 38.4$. Therefore, the number of revertants increased with the increasing concentration until $400 \mu \mathrm{g} /$ plate. However, the number of revertant colonies at a concentration of $800 \mu \mathrm{g} /$ plate and of $1,600 \mu \mathrm{g} /$ plate were decreased as $730.7 \pm 15.6$ and $454.7 \pm 26.5$ with the increasing concentration, respectively. S. Typhimurim TA98 strain is assumed to not grow at its toxicity when the concentration is more than $400 \mu \mathrm{g} /$ plate. Therefore, the smoke condensate concentration determined the $200 \mu \mathrm{g} /$ plate for subsequent experiments.

The test results of mutagenicity of the smoke condensate of herbal cigarette " $\mathrm{A}$ " and general cigarette " $\mathrm{T}$ " in mainstream smoke are shown in Table 6. In the indirect mutagen test $(+\mathrm{S}-9 \mathrm{mix})$, the mutagenicity was $46.67 \pm 3.21$ from the number of spontaneous revertant colonies in the negative control group (DMSO) and mutagenicity was $1238.00 \pm 95.85$ in the positive control group (2-AA). When $200 \mu \mathrm{g} /$ plate of smoke condensate was added, mutagenicity of general cigarette " $T$ " was $518.7 \pm 30.0$. Meanwhile, mutagenicity of herbal cigarette "A" was $539.7 \pm 29.7$.

We confirmed that the smoke condensates of herbal cigarette " $A$ " could induce mutagenicity, and its degree is higher than the general cigarette "T" with the same tar level.

We concluded that some toxic components also exist in the mainstream smoke of herbal cigarette " $\mathrm{A}$ " in large amounts similar to general cigarette. Although tobacco-spe- 
Table 6. The mutagenicity test of smoke condensate

\begin{tabular}{lcc}
\hline \hline $\begin{array}{c}\text { Treatment } \\
(+\mathrm{S}-9 \text { mix })\end{array}$ & $\begin{array}{c}\text { Concentration } \\
(\mu \mathrm{g} / \text { plate })\end{array}$ & Revertants/plate \\
\hline Spontaneous & & $46.67 \pm 3.21$ \\
Control (2-AA) & 1 & $1238.00 \pm 95.85$ \\
Smoke condensate & & \\
"T" & 200 & $518.67 \pm 29.96$ \\
"A" & 200 & $539.67 \pm 29.70$ \\
\hline
\end{tabular}

Values are expressed as mean \pm S.D. $(n=3)$. Statistical analysis of data was analyzed using ANOVA.

" $T$ ": general cigarette with the contents same tar. " $A$ ": herbal cigarette made in Artemisia as raw material.

cific components such as nicotine and TSNA were not detected, the smoke condensates of herbal cigarette " $A$ " have mutagenic potential similar to general cigarette. Hence, the chemical and biological safety of herbal cigarettes should be assessed periodically.

\section{REFERENCES}

1. Green, C.R. and Rodgman, A. (1996) The Tobacco Chemists' Research Conference: a half century forum for advances in analytical methodology of tobacco and its products. Recent Adv. Tob. Sci., 22, 131-306.

2. Perfetti, T.A. and Rodgman, A. (2011) The complexity of tobacco and tobacco smoke. Beitr. Tabakforsch. Int., 24, 215232.

3. Smith C.J., Livingston, S.D. and Doolittle, D.J. (1997) An International literature survey on 'IARC Group 1 Carcinogens' reported in mainstream cigarette smoke. Food Chem. Toxicol., 35, 1107-1130.

4. Smith, C.J., Perfetti, T.A., Rumple, M.A., Rodgman, A. and Doolittle, D.J. (2000) "IARC group 2A Carcinogens" reported in cigarette mainstream smoke. Food Chem. Toxicol., 38, 371383.

5. Smith C.J., Perfetti, T.A., Rumole, M.A., Rodgman, A. and Doolittle, D.J. (2000) "IARC group 2B Carcinogens" reported in mainstream cigarette smoke. Food Chem. Toxicol., 38, 825848.

6. Hoffmann, D. and Hoffmann, I. (1998) Tobacco smoke components. Beitr. Tabakforch. Int., 18, 49-52.

7. Veltel, D. and Hoheneder, A. (1996) Characterization of cigarette smoke-induced micronuclei in vitro. Exp. Toxicol. Pathol., 48, 548-550.

8. Ames, B.N., Mccann, J. and Yamasaki, E. (1975) Methods for detecting carcinogens and mutagens with the Salmonella/ mammalian-microsome mutagenicity test. Mutat. Res., 31, 347-364.

9. Hughes, J.R., Keely, J. and Naud, S. (2004) Shape of the relapse curve and long-term abstinence among untreated smokers. Addiction, 99, 29-38.

10. Gourlay, S.G., Forbes, A., Marriner, T., Pethica, D. and McNeil, J.J. (1995) Double blind trial of repeated treatment with transdermal nicotine for relapsed smokers. $B M J, \mathbf{3 1 1}$, 363-366.
11. Lee, E.S. and Seo, H.G. (2007) The factors associated with successful smoking cessation in Korea. J. Korean Acad. Fam. Med., 28, 39-44.

12. International Organization for Standardization. (1991) ISO 3402: Tobacco and tobacco products-atmosphere for conditioning and testing. ISO.

13. International Organization for Standardization. (1991) ISO 3308: Routine analytical cigarette-smoking machine -- Definitions and standard conditions. ISO.

14. International Organization for Standardization. (2000) ISO 4387: cigarettes - determination of total and nicotine free dry particulate matter using a routine analytical smoking machine. ISO.

15. International Organization for Standardization. (2013) ISO 10315: cigarettes - Determination of nicotine in smoke condensates - Gas-chromatographic method. ISO.

16. International Organization for Standardization. (1999) ISO 10362-1: cigarettes - Determination of water in smoke condensates - Gas-chromatographic method. ISO.

17. International Organization for Standardization. (2007) ISO 8454: cigarettes-determination of carbon monoxide in the vapour phase of cigarette smoke-NDIR method. ISO.

18. Health Canada. (1999) Official Method T-102: Determination of 1- and 2-Aminonaphthalene and 3- and 4-Aminobiphenyl in Mainstream Tobacco Smoke. Health Canada, Canada.

19. International Organization for Standardization. (2008) ISO 22634: cigarettes - Determination of Benzo[a]pyrene in cigarettes Mainstream Smoke - Method Using Gas Chromatography/ Mass Spectrometry; International Organization for Standardization. ISO.

20. Health Canada. (1999) Official Method T-114: Determination of Phenolic Compounds in Mainstream Tobacco Smoke. Health Canada, Canada.

21. CORESTA. (2014) Recommended Method N ${ }^{0} 75$ : Determination of Tobacco Specific Nitrosamines in Mainstream cigarette Smoke by LC-MS/MS. CORESTA, pp. 1-13.

22. Maron, D.M. and Ames, B.N. (1983) Revised methods for the Salmonella mutagenicity test. Mutat. Res., 113, 173-215.

23. Kessler, D.A., Witt, A.M., Barnett, P.S., Zeller, M.R., Natanblut, S.L., Wilkenfeld, J.P., Lorraine, C.C., Thompson, L.J. and Schultz, W.B. (1996) The Food and Drug Administration's regulation of tobacco products. N. Engl. J. Med., 335, 988-994.

24. Baker, R.R. (1975) The formation of the oxides of carbon by the pyrolysis of tobacco. Beitr. Tabakforsch., 8, 16-27.

25. Schlotzhauer, W.S. and Schmeltz, I. (1969) Pyrogenesis of aromatic hydrocarbons present in cigarette smoke II: pyrolytic products of some representative constituents of the hexane soluble fraction of tobacco. Beitr. Tabakforsch. Int., 5, 5-8.

26. Chen, P.X. and Moldoveanu, S.C. (2003) Mainstream smoke chemical analyses for $2 \mathrm{R} 4 \mathrm{~F}$ Kentucky reference cigarette. Beitr. Tabakforsch. Int., 20, 448-458.

27. Baker, R.R. and Bishop, L.J. (2004) The pyrolysis of tobacco ingredients. J. Anal. Appl. Pyrolysis, 71, 223-311.

28. Moldoveanu, S.C. and Borgerding, M. (2007) Formation of tobacco specific nitrosamines in mainstream cigarette smoke; part 1, FTC smoking. Beitr. Tabakforsch. Int., 23, 19-31. 